\title{
SiMYB3 in Foxtail Millet (Setaria italica) Confers Tolerance to Low-Nitrogen Stress by Regulating Root Growth in Transgenic Plants
}

\author{
Linhao Ge ${ }^{1,+}{ }^{+}$, Yining Dou ${ }^{1, \dagger}$, Maomao Li ${ }^{2,+}$, Pengju Qu ${ }^{1}$, Zhang He ${ }^{1}, \mathrm{Y} \mathrm{Liu}^{3}$, Zhaoshi Xu ${ }^{1} \mathbb{D}$, \\ Jun Chen ${ }^{1}$, Ming Chen ${ }^{1, *}$ and Youzhi Ma ${ }^{1, *}$ \\ 1 National Key Facility for Crop Genetic Resources and Genetic Improvement, Key Laboratory of Crop \\ Genetics and Breeding, Ministry of Agriculture/Institute of Crop Sciences, Chinese Academy of Agricultural \\ Sciences, Beijing 100081, China; beatsgg@163.com (L.G.); douyining12@163.com (Y.D.); \\ 13610642179@163.com (P.Q.); hz384298890@163.com (Z.H.); xuzhaoshi@caas.cn (Z.X.); \\ chenjun01@caas.cn (J.C.) \\ 2 Rice Research Institute, Jiangxi Academy of Agricultural Sciences/ Rice National Engineering Laboratory, \\ Nanchang 330200, China; 1mm3056@163.com \\ 3 Xiangyang Academy of Agricultural Sciences, Xiangyang 441057, China; myseaky_2007@163.com \\ * Correspondence: chenming02@caas.cn (M.C.); mayouzhi@caas.cn (Y.M.) \\ + These authors contributed equally to this work.
}

Received: 4 October 2019; Accepted: 13 November 2019; Published: 15 November 2019

\begin{abstract}
Foxtail millet (Setaria italica), which originated in China, has a strong tolerance to low nutrition stresses. However, the mechanism of foxtail millet tolerance to low-nitrogen stress is still unknown. In this study, the transcriptome of foxtail millet under low-nitrogen stress was systematically analyzed. Expression of 1891 genes was altered, including 1318 up-regulated genes and 573 down-regulated genes. KEGG (Kyoto Encyclopedia of Genes and Genomes) analysis revealed that $3 \%$ of these genes were involved in membrane transport and $5 \%$ were involved in redox processes. There were 74 total transcription factor (TF) genes in the DEGs (differentially expressed genes), and MYB-like transcription factors accounted for one-third (25) of the TF genes. We systematically analyzed the characteristics, expression patterns, chromosome locations, and protein structures of 25 MYB-like genes. The analysis of gene function showed that Arabidopsis and rice overexpressing SiMYB3 had better root development than WT under low-nitrogen stress. Moreover, EMSA results showed that SiMYB3 protein could specifically bind MYB elements in the promoter region of TAR2, an auxin synthesis related gene and MYB3-TAR2 regulate pair conserved in rice and foxtail millet. These results suggested that SiMYB3 can regulate root development by regulating plant root auxin synthesis under low-nitrogen conditions.
\end{abstract}

Keywords: foxtail millet; low nitrogen stress; transcriptome analysis; MYB-like transcription factor; transgenic plants

\section{Introduction}

Nitrogen is an essential nutrient for plant growth [1]. Because of the high demand for nitrogen, plant growth and development are often limited by insufficient nitrogen supply [2,3]. The root is the main organ by which plants obtain nitrogen from soil, and morphological and physiological characteristics of the root are important for effective nitrogen use in plants. Changes in root structure have allowed plants to develop functions that improve their adaptability to various environments [4-7]. Studies have shown that many mineral nutrients affect root development by affecting the biosynthesis, transport, and signal transduction of plant hormones [8-10]. 
Low nitrate stress treatment can induce biosynthesis of auxin in the root [11-13]. In addition to the transport of auxin, the signaling transduction of the auxin hormone in the root is affected by low-nitrogen stress. The auxin-resistant mutant axr4 shows no root developmental changes when it lacks nitrate, which provides evidence of overlap between auxin and nitrate signaling pathways [14]. Plants have many active auxins, and IAA is the most thoroughly studied natural auxin [15]. Two major pathways for IAA biosynthesis have been proposed: the tryptophan (Trp)-independent and Trp-dependent pathways. In Trp-dependent IAA biosynthesis, four pathways have been postulated in plants: (i) the indole-3-acetamide (IAM) pathway; (ii) the indole-3-pyruvic acid (IPA) pathway; (iii) the tryptamine (TAM) pathway; and (iv) the indole-3-acetaldoxime (IAOX) pathway [16]. Trp aminotransferase TAA1 and its close homologs TAR1 and TAR2 convert L-Trp to IPyA [17,18]. Multiple lines of evidence suggest that the IPyA pathway is the primary mechanism for de novo synthesis of auxin in plants [19]. Mutations in TAR2 result in decreased lateral root development under low-nitrogen conditions and low $\mathrm{N}$-stimulated lateral root development is dependent on auxin, which is involved in root synthesis by TAR2 [20].

Transcription factors (TFs) play an extremely important role in plants by regulating the expression of stress-related genes, which regulates growth and adaptation to environmental changes [21-23]. The MYB TFs are widely involved in secondary metabolic pathways (including anthocyanin pathways), growth, signal transduction, and disease resistance pathways in plants [24]. Based on the number and location of MYB domains, MYB is divided into four main groups: 1R (R1/2, R3-MYB), 2R (R2R3-MYB), 3R (R1R2R3-MYB), and 4R, which contain four R1/R2-like repeats [25]. R2R3-like MYBs are involved in phenylpropanoid metabolism, the anthocyanin biosynthetic pathway, and lignin synthesis in many plants [26-30]. R2R3-MYBs are also involved in a variety of phytohormone signaling pathways, like salicylic acid [31], abscisic acid [32], gibberellic acid [33], and jasmonic acid [34]. MYB TFs are also involved in the regulation of abiotic stresses such as nutrient starvation in plants, and the MYB-like TFs are involved in flavonol synthesis, which is partially affected by nitrogen deficiency [35]. The R2R3-MYB-like TFs control not only the regulation of flavonoid biosynthesis, but also the regulation of epidermal cell differentiation and cell patterning in root hair development $[24,36]$. Low-nitrogen-responsive MYB members, such as ATR1 and ATR2, are involved in higher plant regulation under conditions of nitrogen deficiency [37,38].

Foxtail millet (Setaria italica) is one of the oldest crops in the world, and it is believed that cultivation may have begun in Gansu, northwestern China, in 5900 BP [39]. Foxtail millet grows in arid soils and does not require high levels of nitrogen fertilizers. This suggests that foxtail millet has a high tolerance for low-nitrogen stress, which is advantageous for food production in developing countries [40]. Its drought-resistant properties and low-nitrogen stresses, along with its small diploid genome $(\sim 510 \mathrm{Mb})[41,42]$, make foxtail millet an ideal model species to study drought response and low-nitrogen stresses in monocotyledons [43,44]. Additionally, foxtail millet root systems are generally strong, which could be related to its strong resistance to drought and low-nitrogen stresses $[45,46]$. Recently, functional genomics research of foxtail millet has begun, but the mechanism of strong stress resistance of foxtail millet, especially the relationship between stress resistance and the root development of millet, is still largely unknown.

In this study, we analyzed the transcriptome of foxtail millet under low-nitrogen stress through RNA-seq. We found that under low-nitrogen stress, the number of MYB TFs was the highest compared to the other TF families. Based on gene function analysis, MYB-like TF SiMYB3 significantly improved the low-nitrogen tolerance of transgenic plants grown on media and under field conditions. At the same time, SiMYB3 affected the root development of transgenic plants by regulating the expression of auxin synthesis-related gene TAR2, which may be the mechanism by which SiMYB3 improves plant tolerance to low-nitrogen stress. This study has increased our understanding of the stress-resistant regulatory network of foxtail millet. 


\section{Results}

\subsection{RNA-Seq Analyses of Low-Nitrogen-Induced Foxtail Millet}

To obtain a global view of transcriptome profiles relevant to the $N$-deficient treatment in Chinese foxtail millet Longgu 25, the high throughput RNA-Seq analyses on poly $\left(\mathrm{A}^{+}\right)$-enriched RNAs from the $\mathrm{CK}$ and Low Nitrogen treatment (LN) libraries were performed using the Solexa/Illumina platform. The results of transcriptome analysis showed that under low-nitrogen stress, there were 1889 differentially expressed genes (DEG) including 1317 up-regulated genes and 572 down-regulated genes ( $\log _{2} \geq$ 1 or $\left.\log _{2} \leq-1\right)$ (Supplementary Table S1). These DEGs were enriched in different GO terms by three classification methods, including biological processes (319 GO terms) (Supplementary Table S2), cell components (65 GO terms) (Supplementary Table S3), and molecular functions (187 GO terms) (Supplementary Table S4). Some of the GO terms are shown in Figure S1A and some GO terms, such as response to stimulus (biological process) and antioxidant activity (molecular function), were related to the stress response. To identify the most important biochemical and metabolic pathways related to the DEGs, we performed a KEGG analysis (Figure S1B). The results showed that 1103 DEGs were enriched in 113 pathways and most DEGs were involved in four main pathways, including metabolic pathway (303 genes), biosynthesis of secondary metabolites (251 genes), plant-pathogen interaction (163 genes), and plant hormone signal transduction (107) (Figure S1B). DEGs were involved in different processes, including protein phosphorylation (4\%), transmembrane transport $(3 \%)$, and the oxidation reduction process (5\%) in foxtail millet (Figure S1C).

Because transcription factors (TFs) play an important role in regulating plant stress response, we selected TF genes from DEGs under low-nitrogen treatment for further analysis. The results showed that a total of 74 TFs (58 upregulated, 16 downregulated) were involved in low-nitrogen stress response in foxtail millet. These $74 \mathrm{TF}$ genes were from different gene families, including $25 \mathrm{MYB}$ (20 up, 5 down), 8 bZIP (7 up, 1 down), 8 WRKY (6 up, 2 down), 7 AP2 (3 up, 4 down), 6 MADS-box (6 up, 0 down), 5 NF-Y (5 up, 0 down), and 24 other (10 up, 14 down) (Figure 1A,B). In those gene families, the number of TFs from the MYB gene family was the highest, suggesting that MYB-like genes play more important roles in the response to low-nitrogen stress in foxtail millet. MYB proteins represent one of the largest transcription factor families in plants, and all 209 S. italica MYB (SiMYB) genes were physically mapped onto nine chromosomes of foxtail millet [47]. Based on these results, we focused on the MYB gene family for further analyses. 


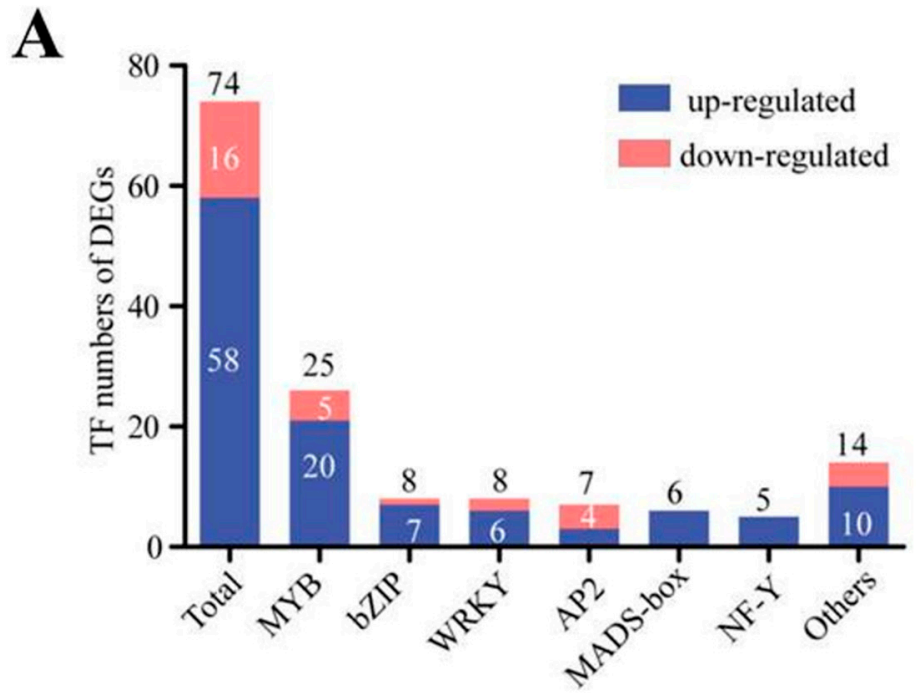

B

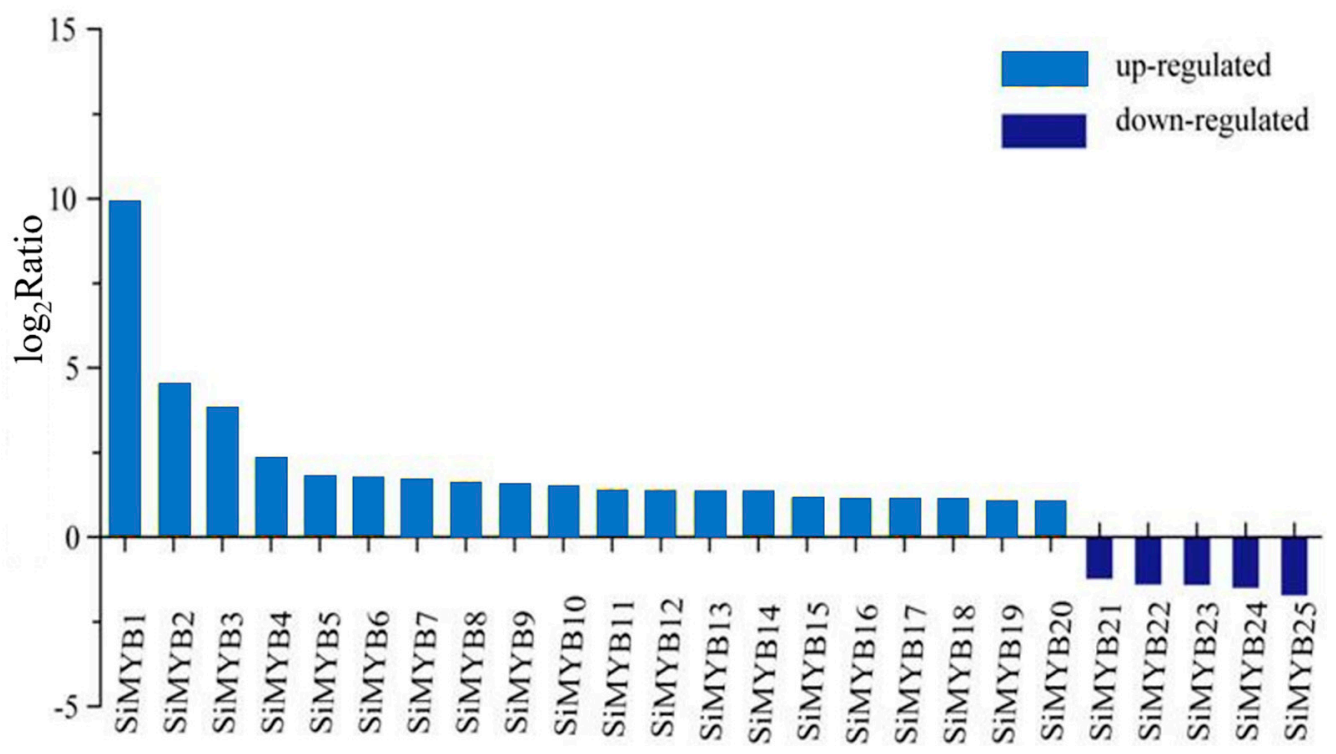

Figure 1. RNA-seq analysis of low-nitrogen treatment of four-leaf stage foxtail millet. (A) Transcription factor gene classification of DEGs. There were 74 transcription factors in 1889 DEGs. (B) Differential expression fold analysis of SiMYB genes in response to low-nitrogen stress in foxtail millet. The value of the Y-axis represents the $\log _{2}$ Ratio.

2.2. Characteristics Analysis of 25 MYB-Like Transcription Factors in Response to Low-Nitrogen Stress in Foxtail Millet

We named the 25 MYB TFs SiMYB1 as SiMYB25 based on high to low gene expression levels under low-nitrogen conditions (Figure 1B). Given that the genes of the MYB family were systematically analyzed and named [47], we have shown the names associated with them in Supplementary Table S5 (the biochemical characteristics of 25 MYB TFs are displayed). The nucleotide sequence lengths of 25 MYB-like TFs varied greatly from 774 to $4764 \mathrm{bp}$; the amino acid sequence length of the MYB TF members varied between 116 and 507 amino acids. Through the prediction of protein domains, 25 MYB-like proteins contained a conserved DNA binding domain (Pfam PF00249) and at least one helix-turn-helix (HTH) domain. In order to analyze the evolutionary relationships of these 25 MYB genes within the gene family, phylogenetic trees were constructed based on multiple sequence alignments (Figure 2A). The results showed that the MYB-like protein family was divided into two subfamilies, including MYB1R and R2R3-MYB (Figure 2A). The protein structure analysis showed 
that the MYB1R subfamily protein contained only one HTH domain and the R2R3-MYB subfamily contained two HTH domains (Figure 2A). The loci of different chromosomes of 25 SiMYB-like genes are shown in Figure 2B.

A

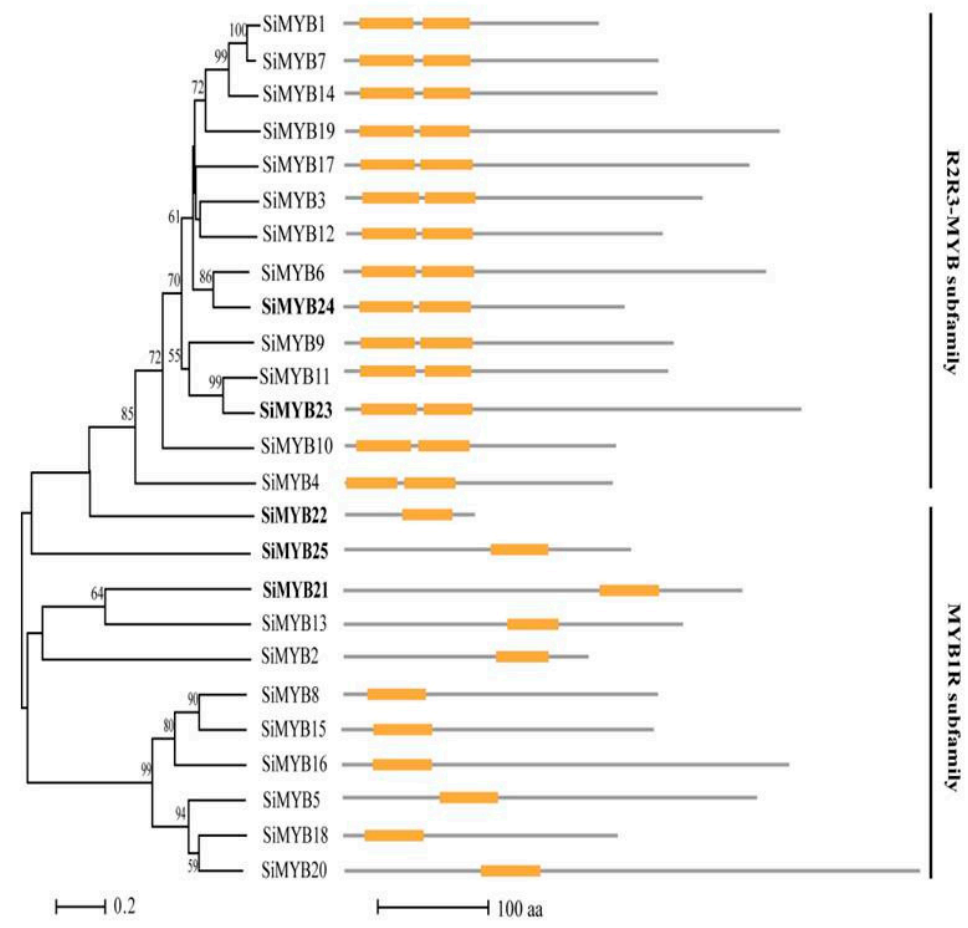

B

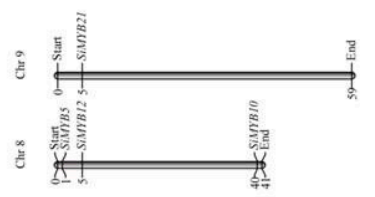

$\tilde{\xi}$
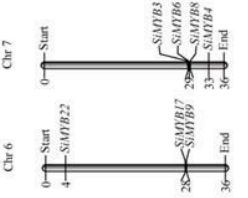

$\tilde{\xi}$

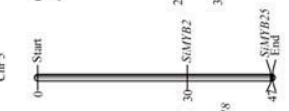

范
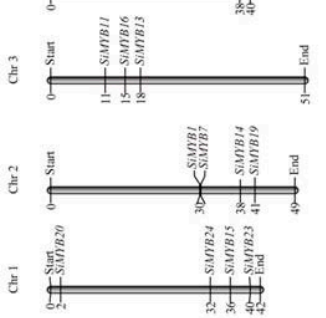

Figure 2. Phylogenetic and protein structure analysis of the SiMYBs gene family in foxtail millet. (A) Phylogenetic tree of SiMYBs gene family in foxtail millet. Bold names represent downregulated genes. Protein structure of SiMYBs gene family in foxtail millet. The yellow box represents DNA binding domain. (B) Chromosomal localization of the SiMYBs gene family in foxtail millet. Phylogenetic trees were constructed using MEGA 6.0 with the neighbor-joining method [48] and 1000 bootstrap replications.

\subsection{Subcellular Localization, Expression Pattern, and Gene Functions of SiMYB3}

Since genetic transformation of foxtail millet has been unsuccessful, we transformed some MYB members into Arabidopsis and rice to identify the gene functions of the 25 MYB TFs. Our results indicated that overexpression of SiMYB3 promoted root development under low-nitrogen conditions in transgenic Arabidopsis (Figure 3). Therefore, we chose SiMYB3 for further analysis and have only reported the results of the study on SiMYB3 in this paper. 
A
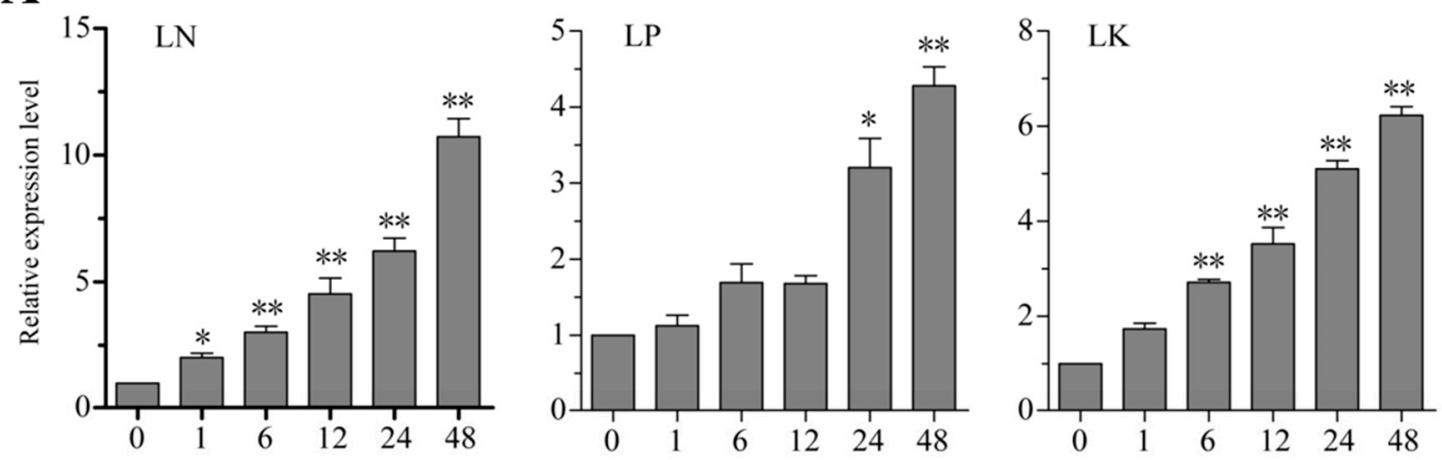

B

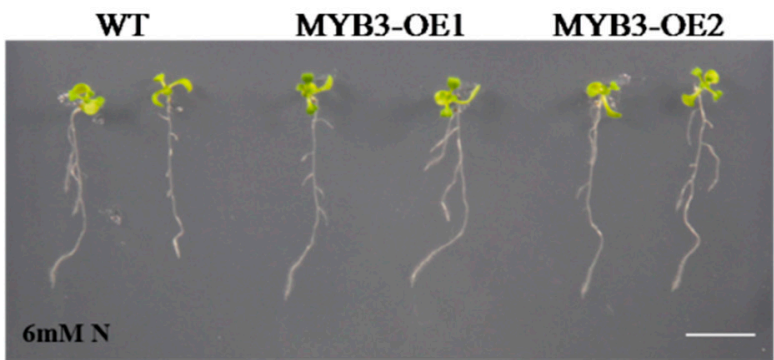

D

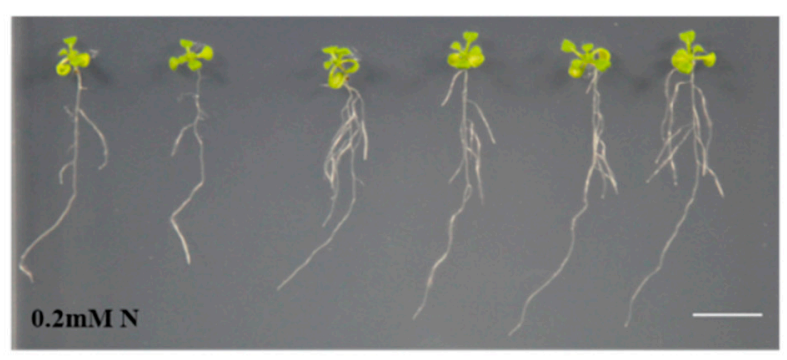

C
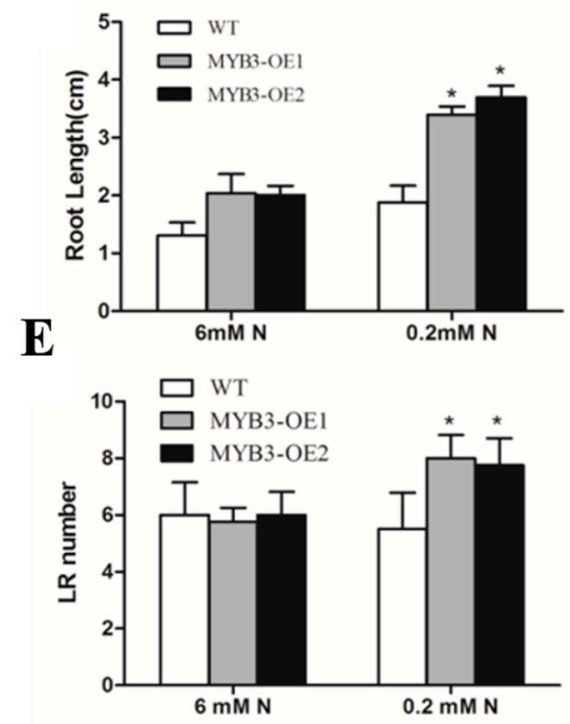

Figure 3. Expression pattern analysis of SiMYB3, and over-expression of SiMYB3 in Arabidopsis increased the root growth of seeds under low-nitrogen treatment. (A) Expression profile analysis of SiMYB3 under Low Nitrogen (LN), Low Phosphorus (LP), and Low Potassium (LK) treatment conditions. Bar $=5 \mu \mathrm{m}$. B-E: Seeds were germinated on 1/2 MS (Nitrogen free) medium supplemented with different concentrations of Nitrogen $(0.2$ and $6 \mathrm{mM})$. (B) Control $(6 \mathrm{mM} \mathrm{N})$; (C) measurements of total root length; (D) LN treatment $(0.2 \mathrm{mM} \mathrm{N})$; (E) measurements of number of lateral roots. Bar $=1 \mathrm{~cm}$. Each data point is the mean $( \pm \mathrm{SE})$ of three experiments. Statistical significance was determined using Student's t-tests $\left({ }^{*} p<0.05,{ }^{* *} p<0.01\right.$ ). To identify gene function, we transformed SiMYB3 into dicotyledonous model plants (Arabidopsis) and monocotyledonous model plants (rice). The expression of SiMYB3 in transgenic plants was verified by RT-PCR (Figure S2).

Expression of SiMYB3 was induced by different low nutrient stresses, including low-nitrogen, low phosphorus, and low potassium. Among these, nutrient stress-induced expression of SiMYB3 under low-nitrogen stress was the highest, and the expression of SiMYB3 was the highest (11 times higher than untreated) at $48 \mathrm{~h}$ after treatment (Figure $3 \mathrm{~A})$. Of the 25 low-nitrogen responsive MYB TFs, the inducible expression levels of SiMYB3 ranked third. Phylogenetic trees showed that SiMYB3 was in the R2R3-MYB subfamily and was most closely related to SiMYB12 (Figure 2A). Gene mapping analysis showed that SiMYB3 was located on the seventh chromosome of foxtail millet, closest to SiMYB6 and SiMYB8 (Figure 2B).

In Arabidopsis, the results of gene function analysis under low-nitrogen stress showed that after 10 days, total root length and lateral root number of WT and transgenic plants were similar under 
normal conditions ( $6 \mathrm{mM}$ nitrogen). In contrast, under low-nitrogen treatment ( $0.2 \mathrm{mM}$ nitrogen), the total root length of transgenic lines OE1 and OE2 was significantly longer than those of WT, and the number of lateral roots in transgenic plants was higher than WT (Figure 3B-E). These results indicated that overexpression of SiMYB3 conferred tolerance to low nitrogen in transgenic Arabidopsis.

To test gene function in a monocotyledonous crop, we transformed SiMYB3 into rice after identifying transgenic rice lines. Under the low-nitrogen treatment $(0.2 \mathrm{mM}$ nitrogen), the total root lengths of transgenic rice lines OE4, OE15, and OE28 were significantly longer than those of CK (Figure 4A,B). We completed the tolerance analysis of low-nitrogen stress in the whole growth period of rice in the field for two years in Nanchang City, Jiangxi Province. After two years of study, our results showed that the dry biomass in transgenic lines OE4, OE28, and OE33 were significantly higher than WT (Figure 4E,F). The grain weight, total nitrogen content, and seed nitrogen content of plants all increased in transgenic rice lines when compared to WT (Figure 4).

A

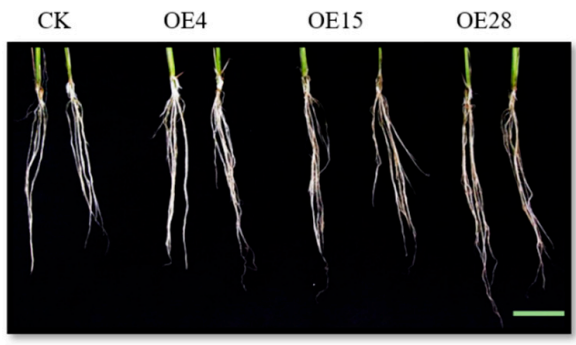

C

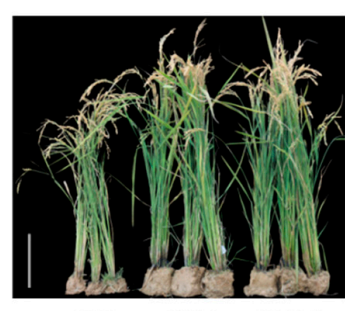

CK OE4 OE15

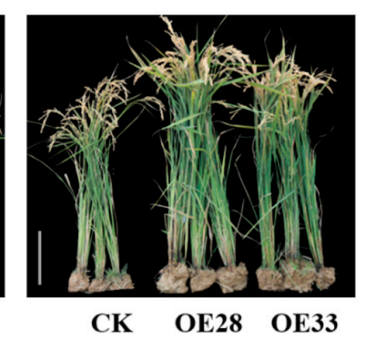

B

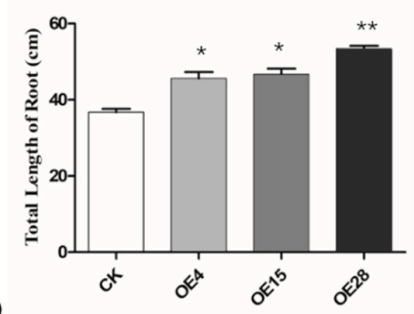

D

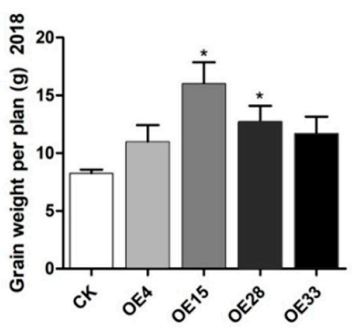

$\mathbf{E}$

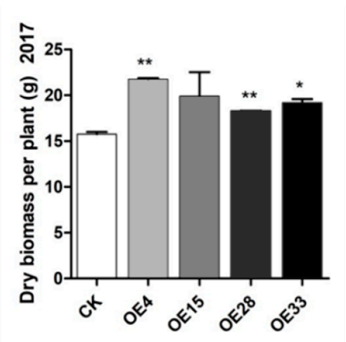

F

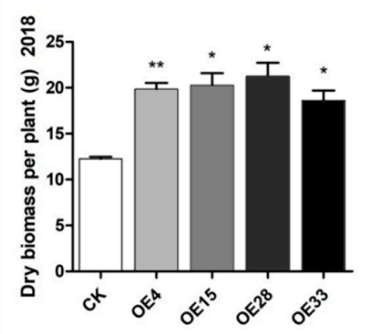

G
$\mathbf{H}$

Figure 4. Phenotype of SiMYB3 transgenic lines in rice. (A) Phenotype of SiMYB3 transgenic lines under Hoagland's $0.2 \mathrm{mM}$ nitrogen liquid medium. (B) Measurements of total root length; Bar $=5 \mathrm{~cm}$. C-H: phenotype analysis of rice SiMYB3-OE lines under no nitrogen fertilizer in the field. (C) Phenotype analysis of SiMYB3 transgenic lines under no nitrogen fertilizer in the field, (D) grain weight per plant, (E,F) dry weight per plant in 2017 and 2018, total nitrogen content (G), and seed nitrogen content (H). $\mathrm{Bar}=10 \mathrm{~cm}$. Values are the mean $\pm \mathrm{SE}$ of at least three replicate experiments. The statistical significance was determined using Student's t-tests. Asterisks indicate the significant difference between SiMYB3 transgenic lines and WT plants $\left({ }^{*} p<0.05,{ }^{* *} p<0.01\right)$.

These results indicated that overexpression of SiMYB3 in transgenic Arabidopsis and rice promoted root growth and increased grain weight under low-nitrogen conditions, suggesting that SiMYB3 conferred tolerance to nitrogen stress in transgenic plants. 
2.4. SiMYB3 Enhanced Tolerance to Low-Nitrogen Stress by Regulating Auxin Synthesis-Related Genes, TAR2, and Low-Nitrogen Stress-Related Genes

To illustrate the regulation mechanism of SiMYB3 in transgenic plants, we detected the expression of some low-nitrogen stress-related genes. The results showed that many genes, including NRT1.1, NIA2, ANR1, NLP7, LBD37, LBD38, LBD39, TAR2, and IPT3, were highly upregulated in the transgenic Arabidopsis (Figure 5A). Among those genes, the induced expression level of TAR2 was higher than WT. Similarly, we found that the rice auxin synthesis-related gene OsFIB [49], which is a homologous gene of TAR2 in rice, also has a high level of expression in transgenic rice (Figure 6). Our results also showed that the foxtail millet auxin synthesis-related gene SiTAR2 is upregulated under low-nitrogen stress (Figure S3A).

A
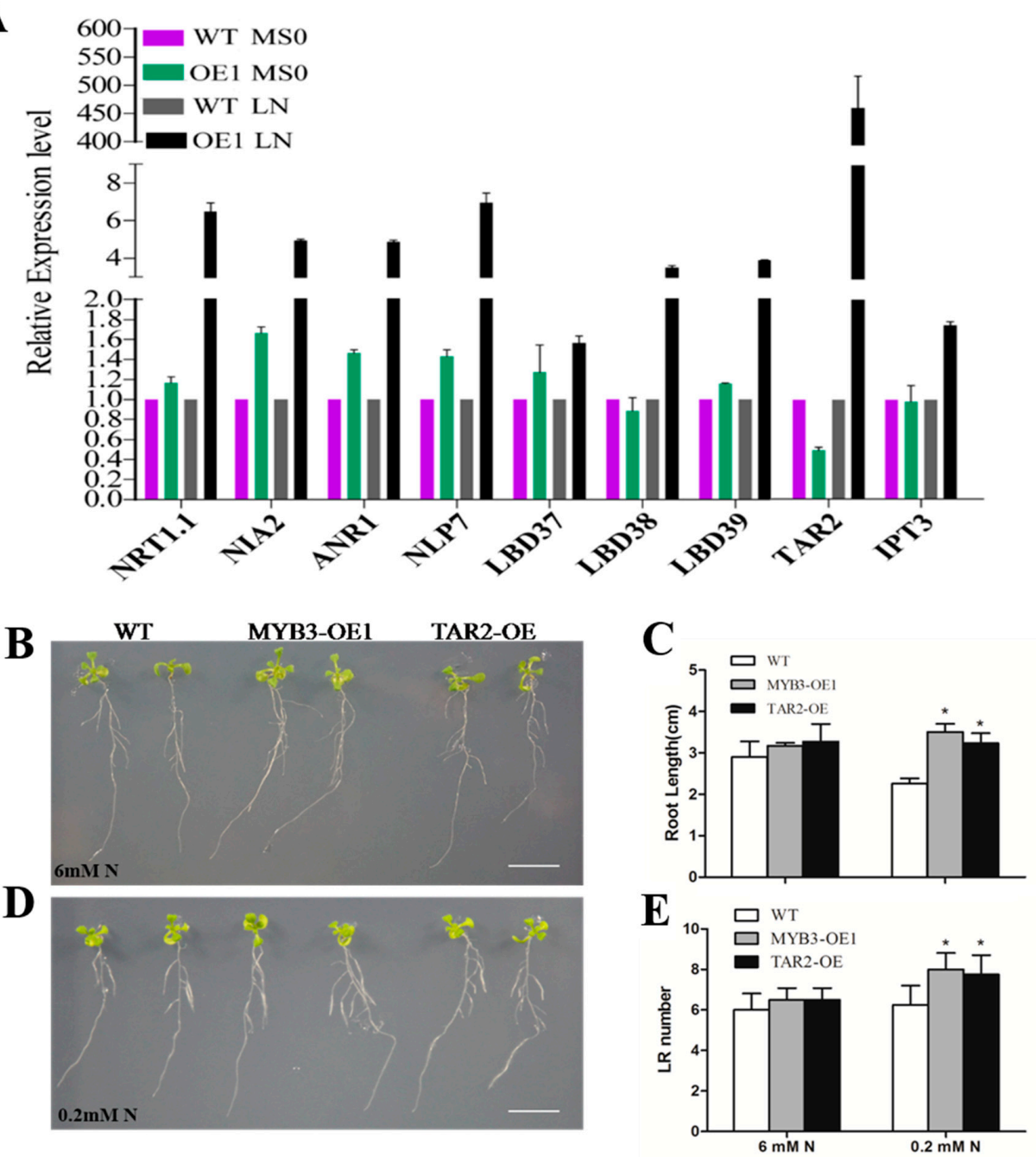

Figure 5. Phenotype analysis of SiMYB3 and TAR2 overexpression line under different conditions. B-E: Seeds were germinated on 1/2 MS (Nitrogen free) medium supplemented with different concentrations of Nitrogen (0.2 and $6 \mathrm{mM}$ ). (A) Levels of gene expression in response to nitrogen under low-nitrogen stress. Fourteen-day-old wild type and overexpression Arabidopsis plants were treated with low nitrogen (0.2 mM nitrogen) and samples were harvested after $24 \mathrm{~h}$ for RNA extraction. (B) Control (6 mM N); (C) Measurements of total root length; (D) low-nitrogen treatment (0.2 $\mathrm{mM} \mathrm{N})$; (E) Measurements of number of lateral roots. Bar $=1 \mathrm{~cm}$. Values are the mean $\pm \mathrm{SE}$ of at least three replicate experiments. Statistical significance was determined using Student's $t$-tests. Asterisks indicate the significant differences between SiMYB3 transgenic lines and WT plants $\left({ }^{*} p<0.05\right)$. 
A

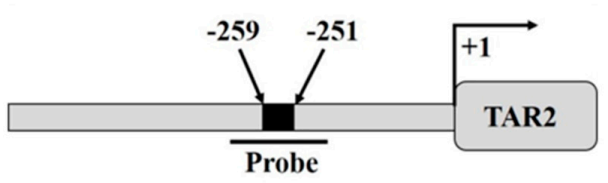

Probe: TTAagtacatgagtTAGgTTCGTAatcCAATA

Mute : TTAAGTACATGATTAATTAACGTAATCCAATA

C
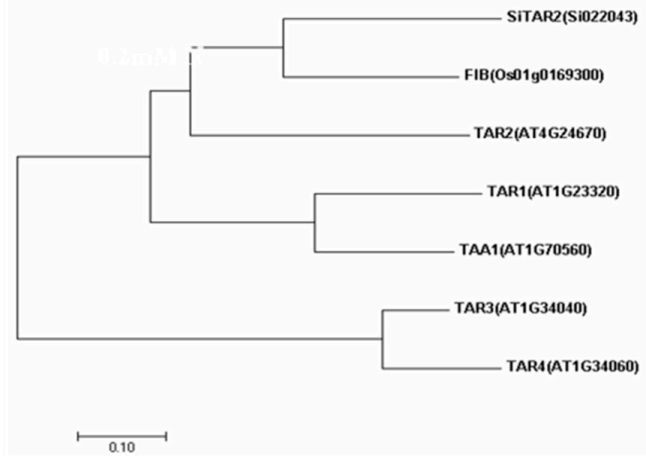

$\mathbf{E}$

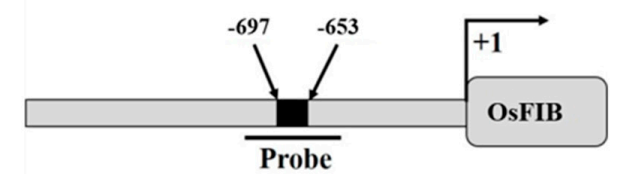

Probe:GCGATAGAATGTGTCGTATCCCGAGCTAGTTTTGTTCGAACATACAGCC

Mute : GCGATAGAATGTGTCAAAAAAGAgCTAGTTTTGTTCGACATACAGCC
B

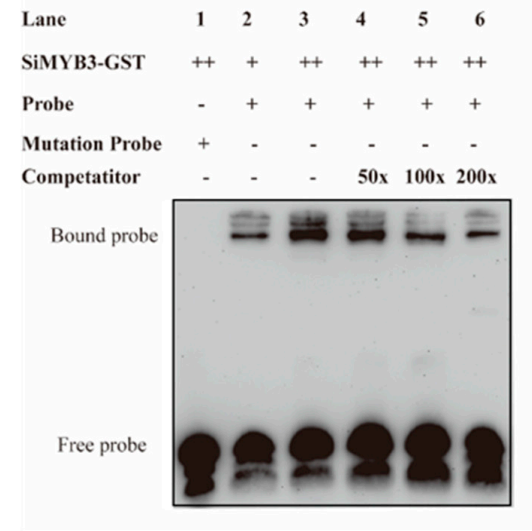

D

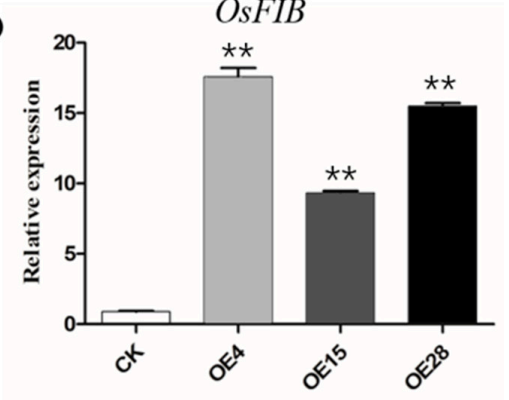

F

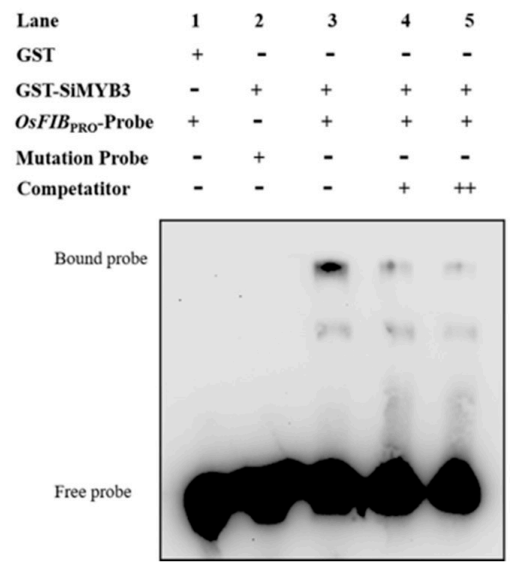

Figure 6. SiMYB3 regulates the expression of the auxin synthesis gene. (A) Schematic diagram of the TAR2 promoter region showing the MYB binding motifs. (B) Electrophoretic mobility shift assays (EMSA) indicating SiMYB3 binding specific MYB-like motifs. (C) Phylogenetic tree of TAR2 family members from Arabidopsis, rice, and foxtail millet. (D) Differential expression of OsFIB gene in rice transgenic lines under low-nitrogen treatment. (E) Schematic diagram of OsFIB promoter region showing the MYB binding motifs. (F) Electrophoretic mobility shift assays (EMSA) indicating SiMYB3 binding specific MYB-like motifs. Values are the mean \pm SE of at least three replicate experiments. Statistical significance was determined using Student's $t$-tests. Asterisks indicate the significant differences between SiMYB3 transgenic lines and CK plants.

We then compared phenotypes of two transgenic plants overexpressing SiMYB3 (OE1) and TAR2 (TAR2-OE) under low-nitrogen stress (Figure 5B-E). The results showed that there was no difference in total root length or lateral root number between WT and OE1 or TAR2-OE plants under normal conditions (6 mM nitrogen), but under low-nitrogen stress ( $0.2 \mathrm{mM}$ nitrogen), the phenotype of OE1 was similar to TAR2-OE. The total root length and lateral root number of OE1 and TAR2-OE were significantly larger than WT (Figure 5C,E). These results suggested that SiMYB3 and TAR2 play similar 
roles in Arabidopsis during a low-nitrogen stress response. To further identify the binding activity of SiMYB3 on the promoter of TAR2, we completed an EMSA assay of SiMYB3 in vitro. We analyzed all cis-elements $2 \mathrm{~kb}$ upstream of the TAR2 gene and found some MYB elements. To confirm the binding specificity, we performed EMSA using recombinant SiMYB3 and a probe designed using an MYB element in the promoter region of TAR2 (Figure 6A). When the DNA probe was incubated with the SiMYB3 protein, the shifted band was clearly detected (Figure 6B, lanes 2 and 3), but no shifted band was observed when the mutant probe was incubated with SiMYB3 (Figure 6B, lane 1). Additionally, SiMYB3 protein could also bind the promoter region of rice auxin synthesis-related gene OsFIB (Figure 6E,F), and millet auxin synthesis-related gene SiTAR2 (Figure S3).

\section{Discussion}

Foxtail millet has a high tolerance for low-fertility soil [40]. In order to improve the efficiency of fertilizer use in certain crops (particularly Gramineae crops), it is important to clarify how foxtail millet regulates its tolerance to low nutrient stress. To that end, we systematically analyzed the transcriptome of foxtail millet under low-nitrogen treatment. The results showed a total of 1889 DEGs, some of which participated in stress-related GO terms, including the response to stimulus and antioxidant activity. According to the identified pathways, $3 \%$ of the genes were involved in transmembrane transport and 5\% were involved in the oxidation reduction process (Figure S1C). Among those DEGs, there were 74 TF genes belonging to different gene families, including MYB, bZIP, WRKY, AP2, MADS-box, and NF-Y. MYB-like TFs accounted for one-third of the low-nitrogen response TFs, suggesting that MYB-like TFs play an important role in response to low-nitrogen stress in foxtail millet. In Arabidopsis, most nitrogen-related MYB family transcription factors belong to the R2R3-type MYB subfamily $[30,37,50]$. MYB protein represents one of the largest families of transcription factors in plants and plays an important role in a variety of developmental and stress response processes. Currently, 209 MYB-type transcription factors have been identified in foxtail millet [47]. In this study, we found that MYB-like transcription factors that respond to low-nitrogen stress are from two different subfamilies, the R2R3-type MYB subfamily (14 genes) and the MYB1R subfamily (11 genes). Moreover, SiMYB3 is from the R2R3-type MYB subfamily, suggesting that members in this subfamily are important for tolerance to low-nitrogen stress in monocotyledonous and dicotyledonous plants.

We overexpressed the SiMYB3 gene in Arabidopsis and rice. Low-nitrogen experiments at the seedling stage demonstrated that transgenic lines enhanced root development when compared to the wide type (Figures 4 and 5), which suggests that SiMYB3 significantly improved the tolerance of transgenic rice to low-nitrogen stress. In the seedling stage of Arabidopsis and rice, no significant differences in biomass were observed aboveground, but through field experiments, we found that transgenic rice has high biomass and yield (Figure 4C-H). We conclude that SiMYB3 helps plant growth by enhancing root development and promoting nitrogen uptake, stimulating growth in a low-nitrogen environment.

When plants face the challenge of environmental change, the response of the roots is often based on auxin, ethylene, and cytokinin. Understanding how hormones and genes interact to coordinate plant growth in a changing environment is a major challenge in plant developmental biology [51]. We found that under low-nitrogen conditions, the expression level of TAR2 was highly upregulated in the SiMYB3 overexpressing lines (Figure 5A). TAR2 is an auxin biosynthesis-related gene that is induced under low-nitrogen conditions and is involved in the regulation of root growth and nitrogen utilization efficiency [20]. The phenotypes of the SiMYB3 overexpressing line and the TAR2 overexpressing line were similar under low-nitrogen stress conditions (Figure 5B-E). The EMSA experiments demonstrate that SiMYB3 can bind to the promoter region of auxin biosynthesis-related genes (Figure 6). Therefore, we hypothesize that SiMYB3 can enhance plant tolerance to low-nitrogen stress by regulating the expression of auxin biosynthesis-related genes and thereby affecting root growth. We also found that a key nitrate transporter, NRT1.1, was induced in SiMYB3 transgenic plants. NRT1.1 (CHL1/NPF6.3) is an influx carrier participating in the root uptake of $\mathrm{NO}_{3}{ }^{-}[52,53]$. The role of NRT1.1 as a $\mathrm{NO}_{3}{ }^{-}$sensor 
is versatile because it activates different physiological or developmental responses to $\mathrm{NO}_{3}{ }^{-}$via several independent sensing/signaling mechanisms [54]. These results suggest that SiMYB3 also regulates nitrate transport, which affects the tolerance of transgenic plants to low nitrogen levels.

\section{Materials and Methods}

\subsection{Swiss-Prot, GO, and KEGG Pathway Annotation}

We performed Swiss-Prot function annotation analysis based on the UniProtKB/Swiss-Prot database (http://www.uniprot.org/), GO function annotation analysis based on the GO database (http://geneontology.org/page/go-database), and KEGG pathway annotation analysis based on the KEGG database (http://www.kegg.jp/kegg/ko.html).

\subsection{Gene Structure and cis-Acting Elements}

The TAR2 promoter was evaluated using "Promoter 2.0 Prediction Server" (Promoter 2.0 is available as a web server at http://www.cbs.dtu.dk/services/promoter/) [55]. Cis-acting elements were analyzed using the plant cis-acting element database Plant Care [56].

\subsection{Plant Materials and Growth Conditions}

Arabidopsis thaliana ecotype Columbia (Col-0) was used in this study. myb9 (SALK_149765C) was obtained from the Arabidopsis Biological Resource Center (ABRC). Professor Yiping Tong (Institute of Genetics and Developmental Biology, Chinese Academy of Sciences) provided the seeds of TAR2-OE Arabidopsis. The vernalized seeds were plated on MS plates containing 1\% agar and 1\% sucrose. The plates were oriented vertically for the seed germination and plant growth stages in growth chambers set at $22{ }^{\circ} \mathrm{C}$, under a $16 \mathrm{~h} \mathrm{light} / 8 \mathrm{~h}$ dark cycle [20]. To generate SiMYB3-OE Arabidopsis plants, we introduced the coding region of SiMYB3 into pBI121, a plant transformation vector, which was controlled by the CaMV35S promoter [57]. The constructs were confirmed by sequencing and then transformed into wild-type plants (Col-0) by the vacuum infiltration method [58]. The transgenic rice seedlings were held at $30^{\circ} \mathrm{C}$ under a $14 \mathrm{~h} \mathrm{light} / 10 \mathrm{~h}$ dark cycle. For rice transformation, SiMYB3 gene was inserted into pCambia1390 vector and SiMYB3 controlled by UBI promoter.

\subsection{Nitrogen Treatments on Media}

High $\mathrm{N}$ media ( $3 \mathrm{mM} \mathrm{NH}_{4} \mathrm{NO}_{3}$ ) and low $\mathrm{N}$ media $\left(0.1 \mathrm{mM} \mathrm{NH}_{4} \mathrm{NO}_{3}\right)$ with $1 \%$ sucrose, $1 \%$ agar, pH 5.8, supplemented with $4 \mathrm{mM} \mathrm{CaCl}_{2}, 1 \mathrm{mM} \mathrm{MgSO}_{4}, 1.5 \mathrm{mM} \mathrm{KH}_{2} \mathrm{PO}_{4}, 1.5 \mathrm{mM} \mathrm{KH}_{2} \mathrm{PO}_{4}, 2 \mathrm{mM}$ $\mathrm{K}_{2} \mathrm{SO}_{4}, 40 \mu \mathrm{M} \mathrm{Na}{ }_{2} \mathrm{Fe}-\mathrm{EDTA}, 60 \mu \mathrm{M} \mathrm{H}_{3} \mathrm{BO}_{3}, 14 \mu \mathrm{M} \mathrm{MnSO}_{4}, 1 \mu \mathrm{M} \mathrm{ZnSO}_{4}, 0.3 \mu \mathrm{M} \mathrm{NaMoO}_{4}, 0.6 \mu \mathrm{M}$ $\mathrm{CuSO}_{4}, 0.4 \mu \mathrm{M} \mathrm{NiCl}_{2}$, and $20 \mathrm{nM} \mathrm{CoCl} 2$ were prepared. Four-day-old seedlings of Arabidopsis or surface-sterilized rice were transferred to either high $\mathrm{N}$ media or low $\mathrm{N}$ media for the stated time periods [20].

\subsection{Field Low-Nitrogen Stress Testing of Transgenic Rice}

To investigate the application potential of SiMYB3, field-tests of T3 generation SiMYB3-OE plants were performed in paddy fields under normal growth conditions during 2017 and 2018. In order to create low-nitrogen field conditions, we chose red soil regions with poor nutrition at the Rice Research Institute, Jiangxi Academy of Agricultural Sciences (Nanchang, China). In order to deplete the available nutrients in the soil, we planted a generation of conventional rice varieties prior to conducting our field experiment. We also measured the soil nutrient content, and the results showed that the nitrogen content in the low-nitrogen treatment field was $36.2 \mathrm{mg} / \mathrm{kg}$, which was lower than that of normal treatment fields $(120.0 \mathrm{mg} / \mathrm{kg})$. To fertilize the field, we used nitrogen $1.8 \mathrm{~kg}, \mathrm{P}_{2} \mathrm{O}_{5} 0.8 \mathrm{~kg}$, and $\mathrm{K}_{2} \mathrm{O}$ $1.2 \mathrm{~kg}$ for every $100 \mathrm{~m}^{2}$ of field under normal treatment. No nitrogen with similar levels of nutritional content was used for low-nitrogen treatment. Between the two years of experiments, we planted rice to 
further deplete the nitrogen levels in the soil. This rice was usually planted in March and transplanted in April of each year.

\subsection{Subcellular Localization}

The ORF of SiMYB3 was cloned into the p16318hGFP vector and fused with the GFP reporter gene under the control of the cauliflower mosaic virus (CaMV) $35 \mathrm{~S}$ promoter. The protoplast transformation was performed using the method described by Asai et al. [59]. The protoplasts were then viewed with a Zeiss LSM 710 NLO laser scanning microscope (Zeiss, Oberkochen, Germany, http://corporate.zeiss.com) with a 488- or 543-nm laser.

\subsection{RNA Isolation and Quantitative Real-Time RT-PCR}

Total RNA was extracted from seedlings using the Total RNA Extraction Kit (TIANGEN, China). The cDNA was synthesized according to the instructions of the Fast Quant RT Super Mix Reverse Transcription Kit (TransGene, Beijing China). Real-time PCR amplification was performed using a Real Master Mix (SYBR Green, Beijing China) kit (TransGene) and a fluorescence quantitative PCR instrument (ABI7500, USA). The relative expression of the gene in different samples was calculated using the $2^{-\Delta \Delta \mathrm{Ct}}$ method, according to the $\mathrm{Ct}$ value at the specific fluorescence threshold for each sample.

\subsection{Protein Purification and Electrophoretic Mobility Shift Assays (EMSA)}

The ORF of SiMYB3 was fused in-frame with GST in p4T-1 and expressed in E. coli DE3, and purified by standard procedures using glutathione agarose beads (GE Healthcare, Pittsburgh, PA, USA). Briefly, $5 \mathrm{~mL}$ of DE3 cells grown overnight and expressing the desired constructs were transferred into $500 \mathrm{~mL}$ of $\mathrm{LB}$ and grown at $37^{\circ} \mathrm{C}$ for $3 \mathrm{~h}(\mathrm{OD}=1.0)$. Isopropyl- $\beta$-d-thiogalactopyranoside (IPTG, $1 \mathrm{mM}$ ) was then added to the media and incubated overnight at $16^{\circ} \mathrm{C}$ to induce protein expression. The bacterial cells were sonicated in PBS with $1 \%$ Triton X-100 and centrifuged at 10,000 g for $10 \mathrm{~min}$ to remove insoluble cell debris. The supernatant was incubated with PBS pre-equilibrated with lutathione agarose beads and rotated at $4{ }^{\circ} \mathrm{C}$ for $4 \mathrm{~h}$. After washing five times with PBS, GST-tagged protein was eluted using $10 \mathrm{mM}$ glutathione. For EMSA, $30 \mathrm{ng}$ of purified GST-SiMYB3 recombinant protein, $400 \mathrm{fmol}$ of biotin-labeled annealed oligonucleotides, $2 \mu \mathrm{L}$ of $10 \times$ binding buffer $(100 \mathrm{mM}$ Tris, $500 \mathrm{mM}$ $\mathrm{KCL}$, and $10 \mathrm{mM}$ DTT, pH 7.5), $1 \mu \mathrm{L}$ of $50 \%$ (v/v) glycerol, $1 \mu \mathrm{L}$ of $100 \mathrm{mM} \mathrm{MgCl} 2,1 \mu \mathrm{L}$ of $1 \mu \mathrm{g} / \mu \mathrm{L}$ poly (dI-dC), and $1 \mu \mathrm{L}$ of $1 \%(v / v) \mathrm{NP}-40$ were combined and double-distilled water was added to a final volume of $20 \mu \mathrm{L}$. Biotin-labeled DNA was detected using the LightShift Chemiluminescent EMSA kit (Thermo Scientific, 20148, Waltham, MA, USA).

\section{Conclusions}

In this study, the transcriptome of foxtail millet under low nitrogen stress was systematically analyzed. The analysis of gene function showed that Arabidopsis overexpressing SiMYB3 had higher root length than WT under low nitrogen stress, which was similar to the phenotype in plants overexpressing TAR2, an auxin synthesis-related gene in Arabidopsis. These results suggested that SiMYB3 can regulate root development by regulating plant root auxin synthesis under low nitrogen conditions.

Supplementary Materials: Supplementary materials can be found at http://www.mdpi.com/1422-0067/20/22/ 5741/s1. Figure S1. GO terms and KEGG analysis of differentially expressed genes. The GO biological functions of different expression levels of genes were analyzed by Gene Ontology (Available online: http: //www.geneontology.org/). We conducted KEGG Pathway and enrichment analyses of these genes using the Kyoto Encyclopedia of Genes and Genomes (KEGG) Pathway (Available online: http://www.kegg.jp/). Figure S2. The expression of SiMYB3 in the Arabidopsis or rice transgenic lines. RT-PCR analysis showing the expression of SiMYB3 in transgenic Arabidopsis OE1 and OE2 or transgenic rice OE4, OE15, OE28, and OE33. Total RNAs isolated from WT (Col-0), Arabidopsis OE1 and OE2 or CK (kitaake), OE4, OE15, OE28, and OE33 were subjected to RT-PCR analysis using the primers. The Actin genes of Arabidopsis and rice were used as controls. Figure S3. (A) Differential expression of the SiTAR2 gene in foxtail millet under low-nitrogen treatment. (B) Schematic diagram of SiTAR2 promoter region showing the MYB binding motifs. (C) Electrophoretic mobility shift assays (EMSA) indicating SiMYB3 binding specific MYB-like motifs. Supplementary Table S1. Genes induced and repressed at 1 
$\mathrm{h}$ after SA treatment. Supplementary Table S2. Biological process GO terms of differentially expressed genes. Supplementary Table S3. Cell component GO terms of differentially expressed genes. Supplementary Table S4. Molecular function GO terms of differentially expressed genes. Supplementary Table S5. Twenty-five transcription factors named SiMYB1-25 were significantly differentially expressed genes obtained from the RNA-seq analysis. Supplementary Table S6. List of the primers used in PCR analyses.

Availability of data and materials: The transcriptome data is available in the Sequence Read Archive (SRA) under accession number PRJNA516031. All the supporting data are included as additional files.

Author Contributions: M.C. coordinated the project, conceived and designed the experiments, and edited the manuscript; L.G. performed experiments and wrote the first draft; Y.D. conducted bioinformatics work and conducted experiments; M.L. contributed to planting and collecting experimental materials; P.Q., Y.L. generated and analyzed data; Z.H. assisted in the low-nitrogen treatment test with foxtail millet. Z.X. contributed with editing the manuscript; J.C. provided analytical tools and managed reagents; Y.M. coordinated the project and edited the manuscript. All authors have read and approved the final manuscript.

Funding: This work was supported by key projects of genetic modification (2018 ZX08009-17B); the major genetically modified project (2016ZX08002005), and Study on High-Efficient Breeding Technology of Dwarf Male-Sterile Wheat by Chromosome Loss Method (2017lgij05).

Acknowledgments: We are grateful to Xianmin Diao and Guanqing Jia (Institute of Crop Science, Chinese Academy of Agricultural Sciences) for providing foxtail millet seeds and comments on the revision of the experimental design. Thanks to Yiping Tong for the provision of TAR2-OE seeds.

Conflicts of Interest: The authors declare no conflict of interest.

$\begin{array}{ll}\text { Abbreviations } \\ \text { GO } & \text { Gene Ontology } \\ \text { bp } & \text { Base Pair } \\ \text { cDNA } & \text { Complementary DNA } \\ \text { CK } & \text { Control Check } \\ \text { CDS } & \text { Coding Sequence } \\ \text { RT-PCR } & \text { Reverse Transcription-Polymerase Chain Reaction } \\ \text { WT } & \text { Wild Type } \\ \text { OE } & \text { Overexpression Line } \\ \text { LR } & \text { Lateral Root } \\ \text { LN } & \text { Low Nitrogen } \\ \text { LP } & \text { Low Phosphorus } \\ \text { LK } & \text { Low Potassium } \\ \text { TF } & \text { Transcription Factor }\end{array}$

\section{References}

1. Miller, A.J.; Cramer, M.D. Root nitrogen acquisition and assimilation. Plant Soil 2005, 274, 1-36. [CrossRef]

2. Gilroy, S.; Jones, D.L. Through form to function: Root hair development and nutrient uptake. Trends Plant Sci. 2000, 5, 56-60. [CrossRef]

3. Strahm, B.D.; Harrison, R.B. Nitrate Sorption in A Variable-Charge Forest Soil of the Pacific Northwest. Soil Sci. 2006, 171, 313-321. [CrossRef]

4. Lima, J.E.; Kojima, S.; Takahashi, H.; von Wirén, N. Ammonium triggers lateral root branching in Arabidopsis in an AMMONIUM TRANSPORTER1;3-dependent manner. Plant Cell 2010, 22, 3621-3633. [CrossRef]

5. Remans, T.; Nacry, P.; Pervent, M.; Filleur, S.; Diatloff, E.; Mounier, E.; Tillard, P.; Forde, B.G.; Gojon, A. The Arabidopsis NRT1.1 transporter participates in the signaling pathway triggering root colonization of nitrate-rich patches. Proc. Natl. Acad. Sci. USA 1920, 103, 19206-19211. [CrossRef]

6. Lynch, J. Root Architecture and Plant Productivity. Plant Physiol. 1995, 109, 7-13. [CrossRef] [PubMed]

7. Tian, Q.; Chen, F.; Zhang, F.; Mi, G. Possible Involvement of Cytokinin in Nitrate-mediated Root Growth in Maize. Plant Soil 2005, 277, 185. [CrossRef]

8. Rubio, V.; Bustos, R.; Irigoyen, M.L.; Cardona-López, X.; Rojas-Triana, M.; Paz-Ares, J. Plant hormones and nutrient signaling. Plant Mol. Biol. 2008, 69, 361. [CrossRef]

9. Krouk, G.; Ruffel, S.; Gutiérrez, R.A.; Gojon, A.; Crawford, N.M.; Coruzzi, G.M.; Lacombe, B. A framework integrating plant growth with hormones and nutrients. Trends Plant Sci. 2011, 16, 178-182. [CrossRef] 
10. Li, S.; Tian, Y.; Wu, K.; Ye, Y.; Yu, J.; Zhang, J.; Liu, Q.; Hu, M.; Li, H.; Tong, Y.; et al. Modulating plant growth-metabolism coordination for sustainable agriculture. Nature 2018, 560, 595-600. [CrossRef]

11. Caba, J.M.; Centeno, M.L.; Fernandez, B.; Gresshoff, P.M.; Ligero, F. Inoculation and nitrate alter phytohormone levels in soybean roots: Differences between a supernodulating mutant and the wild type. Planta 2000, 211, 98-104. [CrossRef] [PubMed]

12. Walch-Liu, P.; Ivanov, I.I.; Filleur, S.; Gan, Y.; Remans, T.; Forde, B.G. Nitrogen regulation of root branching. Ann. Bot. 2006, 97, 875-881. [CrossRef] [PubMed]

13. Tian, Q.; Chen, F.; Liu, J.; Zhang, F.; Mi, G. Inhibition of maize root growth by high nitrate supply is correlated with reduced IAA levels in roots. J. Plant Physiol. 2008, 165, 942-951. [CrossRef] [PubMed]

14. Zhang, H.; Jennings, A.; Barlow, P.W.; Forde, B.G. Dual pathways for regulation of root branching by nitrate. Proc. Natl. Acad. Sci. USA 1999, 96, 6529-6534. [CrossRef]

15. Korasick, D.A.; Enders, T.A.; Strader, L.C. Auxin biosynthesis and storage forms. J. Exp. Bot. 2013, 64, 2541-2555. [CrossRef]

16. Mano, Y.; Nemoto, K. The pathway of auxin biosynthesis in plants. J. Exp. Bot. 2012, 63, $2853-2872$. [CrossRef]

17. Stepanova, A.N.; Robertson-Hoyt, J.; Yun, J.; Benavente, L.M.; Xie, D.Y.; Dolezal, K.; Schlereth, A.; Jurgens, G.; Alonso, J.M. TAA1-mediated auxin biosynthesis is essential for hormone crosstalk and plant development. Cell 2008, 133, 177-191. [CrossRef]

18. Tao, Y.; Ferrer, J.L.; Ljung, K.; Pojer, F.; Hong, F.; Long, J.A.; Li, L.; Moreno, J.E.; Bowman, M.E.; Ivans, L.J.; et al. Rapid synthesis of auxin via a new tryptophan-dependent pathway is required for shade avoidance in plants. Cell 2008, 133, 164-176. [CrossRef]

19. Mashiguchi, K.; Tanaka, K.; Sakai, T.; Sugawara, S.; Kawaide, H.; Natsume, M.; Hanada, A.; Yaeno, T.; Shirasu, K.; Yao, H.; et al. The main auxin biosynthesis pathway in Arabidopsis. Proc. Natl. Acad. Sci. USA 2011, 108, 18512-18517. [CrossRef]

20. Ma, W.; Li, J.; Qu, B.; He, X.; Zhao, X.; Li, B.; Fu, X.; Tong, Y. Auxin biosynthetic gene TAR2 is involved in low nitrogen-mediated reprogramming of root architecture in Arabidopsis. Plant J. 2014, 78, 70-79. [CrossRef]

21. Shinozaki, K.; Yamaguchi-Shinozaki, K. Molecular responses to dehydration and low temperature: Differences and cross-talk between two stress signaling pathways. Curr. Opin. Plant Biol. 2000, 3, 217-223. [CrossRef]

22. Kasuga, M.; Liu, Q.; Miura, S.; Yamaguchi-Shinozaki, K.; Shinozaki, K. Improving plant drought, salt, and freezing tolerance by gene transfer of a single stress-inducible transcription factor. Nat. Biotechnol. 1999, 17, 287. [CrossRef] [PubMed]

23. Jaglo-Ottosen, K.R.; Gilmour, S.J.; Zarka, D.G.; Schabenberger, O.; Thomashow, M.F. Arabidopsis CBF1 Overexpression Induces COR Genes and Enhances Freezing Tolerance. Science 1998, 280, 104-106. [CrossRef]

24. Jin, H.; Martin, C. Multifunctionality and diversity within the plant MYB-gene family. Plant Mol. Biol. 1999, 41,577-585. [CrossRef] [PubMed]

25. Liu, J.; Osbourn, A.; Ma, P. MYB Transcription Factors as Regulators of Phenylpropanoid Metabolism in Plants. Mol. Plant 2015, 8, 689-708. [CrossRef]

26. Albert, N.W.; Davies, K.M.; Lewis, D.H.; Zhang, H.; Montefiori, M.; Brendolise, C.; Boase, M.R.; Ngo, H.; Jameson, P.E.; Schwinn, K.E. A conserved network of transcriptional activators and repressors regulates anthocyanin pigmentation in eudicots. Plant Cell 2014, 26, 962-980. [CrossRef]

27. Xie, Q.; Hu, Z.; Zhang, Y.; Tian, S.; Wang, Z.; Zhao, Z.; Yang, Y.; Chen, G. Accumulation and Molecular Regulation of Anthocyanin in Purple Tumorous Stem Mustard (Brassica juncea var. tumida Tsen et Lee). J. Agric. Food Chem. 2014, 62, 7813-7821. [CrossRef]

28. Zhang, Q.; Hao, R.; Xu, Z.; Yang, W.; Wang, J.; Cheng, T.; Pan, H.; Zhang, Q. Isolation and functional characterization of a R2R3-MYB regulator of Prunus mume anthocyanin biosynthetic pathway. Plant Cell Tissue Organ Cult. 2017, 131, 417-429. [CrossRef]

29. Patzlaff, A.; Newman, L.J.; Dubos, C.; Whetten, R.W.; Smith, C.; McInnis, S.; Bevan, M.W.; Sederoff, R.R.; Campbell, M.M. Characterisation of PtMYB1, an R2R3-MYB from pine xylem. Plant Mol. Biol. 2003, 53, 597-608. [CrossRef]

30. Gómez-Maldonado, J.; Avila, C.; Torre, F.; Cañas, R.; Cánovas, F.M.; Campbell, M.M. Functional interactions between a glutamine synthetase promoter and MYB proteins. Plant J. 2004, 39, 513-526. [CrossRef]

31. Raffaele, S.; Rivas, S.; Roby, D. An essential role for salicylic acid in AtMYB30-mediated control of the hypersensitive cell death program in Arabidopsis. FEBS Lett. 2006, 580, 3498-3504. [CrossRef] [PubMed] 
32. Abe, H.; Urao, T.; Ito, T.; Seki, M.; Shinozaki, K.; Yamaguchi-Shinozaki, K. Arabidopsis AtMYC2 (bHLH) and AtMYB2 (MYB) Function as Transcriptional Activators in Abscisic Acid Signaling. Plant Cell 2003, 15, 63-78. [CrossRef] [PubMed]

33. Murray, F.; Kalla, R.; Jacobsen, J.; Gubler, F. A role for HvGAMYB in another development. Plant J. 2003, 33, 481-491. [CrossRef] [PubMed]

34. Lee, M.-W.; Qi, M.; Yang, Y. A Novel Jasmonic Acid-Inducible Rice myb Gene Associates with Fungal Infection and Host Cell Death. Mol. Plant Microbe Interact. 2001, 14, 527-535. [CrossRef] [PubMed]

35. Lea, U.S.; Slimestad, R.; Smedvig, P.; Lillo, C. Nitrogen deficiency enhances expression of specific MYB and bHLH transcription factors and accumulation of end products in the flavonoid pathway. Planta 2007, 225, 1245-1253. [CrossRef] [PubMed]

36. Bernhardt, C.; Lee, M.M.; Gonzalez, A.; Zhang, F.; Lloyd, A.; Schiefelbein, J. The bHLH genes GLABRA3 (GL3) and ENHANCER OF GLABRA3 (EGL3) specify epidermal cell fate in the Arabidopsis root. Development 2003, 130, 6431-6439. [CrossRef] [PubMed]

37. Miyake, K.; Ito, T.; Senda, M.; Ishikawa, R.; Harada, T.; Niizeki, M.; Akada, S.J.P.M.B. Isolation of a subfamily of genes for R2R3-MYB transcription factors showing up-regulated expression under nitrogen nutrient-limited conditions. Plant Mol. Biol. 2003, 53, 237-245. [CrossRef] [PubMed]

38. Bender, J.; Fink, G.R. A Myb homologue, ATR1, activates tryptophan gene expression in Arabidopsis. Proc. Natl. Acad. Sci. USA 1998, 95, 5655-5660. [CrossRef]

39. Yang, X.; Wan, Z.; Perry, L.; Lu, H.; Wang, Q.; Zhao, C.; Li, J.; Xie, F.; Yu, J.; Cui, T.; et al. Early millet use in northern China. Proc. Natl. Acad. Sci. USA 2012, 109, 3726-3730. [CrossRef]

40. Nadeem, F.; Ahmad, Z.; Wang, R.; Han, J.; Shen, Q.; Chang, F.; Diao, X.; Zhang, F.; Li, X. Foxtail Millet [Setaria italica (L.) Beauv.] Grown under Low Nitrogen Shows a Smaller Root System, Enhanced Biomass Accumulation, and Nitrate Transporter Expression. Front. Plant Sci. 2018, 9, 205. [CrossRef]

41. Bennetzen, J.L.; Schmutz, J.; Wang, H.; Percifield, R.; Hawkins, J.; Pontaroli, A.C.; Estep, M.; Feng, L.; Vaughn, J.N.; Grimwood, J.; et al. Reference genome sequence of the model plant Setaria. Nat. Biotechnol. 2012, 30, 555-561. [CrossRef] [PubMed]

42. Zhang, G.; Liu, X.; Quan, Z.; Cheng, S.; Xu, X.; Pan, S.; Xie, M.; Zeng, P.; Yue, Z.; Wang, W.; et al. Genome sequence of foxtail millet (Setaria italica) provides insights into grass evolution and biofuel potential. Nat. Biotechnol. 2012, 30, 549-554. [CrossRef] [PubMed]

43. Jia, G.; Huang, X.; Zhi, H.; Zhao, Y.; Zhao, Q.; Li, W.; Chai, Y.; Yang, L.; Liu, K.; Lu, H.; et al. A haplotype map of genomic variations and genome-wide association studies of agronomic traits in foxtail millet (Setaria italica). Nat. Genet. 2013, 45, 957-961. [CrossRef] [PubMed]

44. Lata, C.; Gupta, S.; Prasad, M. Foxtail millet: A model crop for genetic and genomic studies in bioenergy grasses. Crit. Rev. Biotechnol. 2013, 33, 328-343. [CrossRef] [PubMed]

45. Haling, R.E.; Brown, L.K.; Bengough, A.G.; Valentine, T.A.; White, P.J.; Young, I.M.; George, T.S. Root hair length and rhizosheath mass depend on soil porosity, strength and water content in barley genotypes. Planta 2014, 239, 643-651. [CrossRef]

46. Qi, X.; Xie, S.; Liu, Y.; Yi, F.; Yu, J. Genome-wide annotation of genes and noncoding RNAs of foxtail millet in response to simulated drought stress by deep sequencing. Plant Mol. Biol. 2013, 83, 459-473. [CrossRef]

47. Muthamilarasan, M.; Khandelwal, R.; Yadav, C.B.; Bonthala, V.S.; Khan, Y.; Prasad, M. Identification and molecular characterization of MYB Transcription Factor Superfamily in C4 model plant foxtail millet (Setaria italica L.). PLoS ONE 2014, 3, e109920. [CrossRef]

48. Tamura, K.; Stecher, G.; Peterson, D.; Filipski, A.; Kumar, S. MEGA6: Molecular Evolutionary Genetics Analysis version 6.0. Mol. Biol. Evol. 2013, 30, 2725-2729. [CrossRef]

49. Abu-Zaitoon, Y.M.; Bennett, K.; Normanly, J.; Nonhebel, H.M. A large increase in IAA during development of rice grains correlates with the expression of tryptophan aminotransferase OsTAR1 and a grain-specific YUCCA. Physiol. Plant. 2012, 146, 487-499. [CrossRef]

50. Scheible, W.R.; Morcuende, R.; Czechowski, T.; Fritz, C.; Osuna, D.; Palacios-Rojas, N.; Schindelasch, D.; Thimm, O.; Udvardi, M.K.; Stitt, M. Genome-wide reprogramming of primary and secondary metabolism, protein synthesis, cellular growth processes, and the regulatory infrastructure of Arabidopsis in response to nitrogen. Plant Physiol. 2004, 136, 2483-2499. [CrossRef] 
51. Liu, J.; Moore, S.; Chen, C.; Lindsey, K. Crosstalk Complexities between Auxin, Cytokinin, and Ethylene in Arabidopsis Root Development: From Experiments to Systems Modeling, and Back Again. Mol. Plant 2017, 10, 1480-1496. [CrossRef] [PubMed]

52. Tsay, Y.F.; Schroeder, J.I.; Feldmann, K.A.; Crawford, N.M. The herbicide sensitivity gene CHL1 of Arabidopsis encodes a nitrate-inducible nitrate transporter. Cell 1993, 72, 705-713. [CrossRef]

53. Bouguyon, E.; Perrine-Walker, F.; Pervent, M.; Rochette, J.; Cuesta, C.; Benkova, E.; Martiniere, A.; Bach, L.; Krouk, G.; Gojon, A.; et al. Nitrate Controls Root Development through Posttranscriptional Regulation of the NRT1.1/NPF6.3 Transporter/Sensor. Plant Physiol. 2016, 172, 1237-1248.

54. Bouguyon, E.; Brun, F.; Meynard, D.; Kubes, M.; Pervent, M.; Leran, S.; Lacombe, B.; Krouk, G.; Guiderdoni, E.; Zazimalova, E.; et al. Multiple mechanisms of nitrate sensing by Arabidopsis nitrate transceptor NRT1.1. Nat. Plants 2015, 1, 15015. [CrossRef]

55. Knudsen, S. Promoter2.0: For the recognition of PolII promoter sequences. Bioinformatics 1999, 15, $356-361$. [CrossRef]

56. Lescot, M.; Dehais, P.; Thijs, G.; Marchal, K.; Moreau, Y.; Van de Peer, Y.; Rouze, P.; Rombauts, S. PlantCARE, a database of plant cis-acting regulatory elements and a portal to tools for in silico analysis of promoter sequences. Nucleic Acids Res. 2002, 30, 325-327. [CrossRef]

57. Cui, X.Y.; Du, Y.T.; Fu, J.D.; Yu, T.F.; Wang, C.T.; Chen, M.; Chen, J.; Ma, Y.Z.; Xu, Z.S. Wheat CBL-interacting protein kinase 23 positively regulates drought stress and ABA responses. BMC Plant Biol. 2018, 18, 93. [CrossRef]

58. Bechtold, N.; Pelletier, G. In Planta AgrobacteriumMediated Transformation of Adult Arabidopsis thaliana Plants by Vacuum Infiltration. Methods Mol. Biol. 1998, 82, 259-266.

59. Asai, T.; Tena, G.; Plotnikova, J.; Willmann, M.R.; Chiu, W.L.; Gomez-Gomez, L.; Boller, T.; Ausubel, F.M.; Sheen, J. MAP kinase signalling cascade in Arabidopsis innate immunity. Nature 2002, 415, 977-983. [CrossRef]

(C) 2019 by the authors. Licensee MDPI, Basel, Switzerland. This article is an open access article distributed under the terms and conditions of the Creative Commons Attribution (CC BY) license (http://creativecommons.org/licenses/by/4.0/). 